\title{
DECISION MAKING VIA SYSTEMS THINKING IN MANAGEMENT: EDUCATIONAL ISSUES
}

\author{
M. Kudret Yurtseven \\ Izmir University, Izmir, Turkey \\ Walter W. Buchanan \\ Texas A\&M University, College Station, Texas, USA
}

\section{Abstract}

The aim of this paper is to provide a critical view of the educational issues related to teaching decision making in management studies and to provide a general framework is proposed that will serve as a basis designing new courses, covering some methodologies for handling complexity in decision making. At present, the widely spread approach to teaching the subject matter is mostly restricted to the traditional OR/MS (Operations Research/Management Science) paradigm. This paradigm is based on a set of mathematical tools and suitable for solving well defined decision making problems; it fails in "messy" or complex situations. Systems-based approaches are more promising in complex situations since they provide the decision maker(s) the opportunity to address the problematic situation in its full system context. The framework proposed in the study attempts to complement the traditional OR/MS paradigm rather than replacing it.

Key words: Systems Thinking; Decision Making; Management; Education. 


\section{Introduction}

It is well known that managerial decision making problems can be highly complex, in general, but there is a sub-set of problems that can be formulated in well-structured forms. Such problems are normally handled with the quantitative techniques of the Management Science/Operations Research (MS/OR) paradigmthis paradigm is also known as hard operations research. The major quantitative techniques or tools of the paradigm are mathematical programming, game theory, simulation models, Markov chain models and decision tress. In messy situations, these tools prove to be too rigid and mechanical to be useful. The decision problems faced by top managers at the strategic level are mostly complex and 'messy'. There is usually too much ambiguity involved, and information available for decision making is often uncertain, incomplete, or even distorted. Under such conditions, managers need to describe the problematic situation in its full system context and make use of systems thinking-based methodologies to find satisfactory solutions.

For instance let us consider the situation where an American company is questioning whether to enter a new market in a country like Pakistan or Jordan. This decision is a strategic level kind; hence it is complex. There is bound to be considerable uncertainty and ambiguity related to the country's economic conditions, the stability of markets, consumer behavior, etc. It may not be easy or not possible to find an acceptable solution to this problem through the OR/MS tools. The soft approaches are suitable since the soft issues such as consumer behavior can be included in the model via a combined use of hard and soft modeling approaches. Supposing that the company decided to enter the market, the next decision problem will be of a tactical kind, such as whether to follow an export led market expansion or locally produce the product. Here the solution may or may not require the use of both hard and soft methodologies. The related decision at the lowest level could be whether to hire more local people for some operations. This is an operational problem. Now this problem can be handled by hard approaches without a great deal of difficulty. Another example where complexity may be seen is in managing call centers. Effective operation of a call center requires a sensible balance between conflicting aims, such as waiting times, number of operators, equipment, etc. These variables can be formulated in monetary terms and a solution can be found via mathematical models or simulation models. However, if one wants to include the consequences of long waiting times, such as loss of life or serious injuries, the problem becomes too complex to be handled by purely mathematical models. Similar arguments are valid for ecological systems. The economic activities involved can be measured easily in monetary terms, but not the loss or degradation of the natural environment. The common features in all these problems are: (1) Different people view a problem in 
different ways; (2) The solution is not too obvious; (3) There are usually conflicts on objectives; (4) There may not be enough information to evaluate the consequences of decision choices; (5) The interactions between various elements or aspects may exhibit high computational complexity for human mind to produce a solution; (6) The settings within which these problems exist are systems.

Complexity and decision making in complexity have been studied by a number of researchers in the past. Gorze-Mitka, et.al. (2014) traces the roots of "modern complexity" to the birth of General Systems Theory. The complexity issue was also addressed in Weiner's work on cybernetics and in the work of other important names in systems movement, such as Churchman, Ackoff, Beer, Weinberg, Forrester, and Gigch (Skyttner, 2001 and 2006). In 2005, Jamali suggested that the existing decision-making processes are no longer adequate, and urged educational institutions to teach new approaches to decision-making problems (Jamali, 2005). The new approaches can now be seen in some textbooks. For instance, Pownall's book (2012), Effective Management Decision Making, covers holistic approaches, heuristic decision making and group decision making, as well as more traditional topics. Daellanbach, et.al. (2012) wrote an interesting book, entitled Decision Making Through Systems Thinking, which also reflects recent developments. This book puts considerable emphasis on the application of soft systems thinking (particularly Soft OR and Soft Systems Methodology) to decision making. Similar comments can be made about the book by Maani et.al. (2007), Systems Thinking, System Dynamics: Managing Chaos and Complexity. Here, the approach is based on system modeling by combining both hard and soft approaches and System Dynamics methodology. Skyttner (2001 and 2005) provides a wide perspective and presents decision making process in the context of General Systems Theory. He considers various dimensions of decision making processes, including philosophical, methodological, technological and psychological aspects. He emphasizes the importance of Managerial Cybernetics in handling complex organizational issues. Managerial Cybernetics is also seen as an important methodology by Jackson (2000 and 2003) for handling complex managerial problems; Beer's viable model is noted as a significant methodology in this respect.

There are a number of specific studies on complexity decision making in literature. For instance, Gorzen-Mitka, et. al. (2014) examine complexity decision making issues and argue that strategic decision-making in complex environments requires meta-cognitive skills and a tool-bag for innovative and adaptable decision models beyond linear thinking. The book written by Parnell, et.al. (2011), Decision Making in Systems Engineering and Management, approaches the subject matter from a sytems engineering point of view. The decision making process laid out in 
the book is based on both multiple-objective decision making and value-focused thinking. Problem definition, measuring stakeholder value, designing cretaive solutions, exploring the decision trade space and structuring successful solution implementation phases are all viewed from this perspective. The attractive aspect of this work is that it is very well suited for system life-cycle models.

The material in this paper is presented in the following order: the fundamental role of system thinking in managing complexity is assessed in the next section; this is followed by a discussion of the potential contributions of systems thinking to decision making, the description of the proposed framework, and the major conclusions of the work.

\section{Systems Thinking and Managing Complexity}

Managers today are expected to cope with increasing complexity, change and diversity. They need to handle problems that come as interconnected with other problems, or as 'messes'. Managers have some popular tools available to deal with decision problems, such as scenario planning, benchmarking, value chain analysis, and process re-engineering. The 'quick' solutions generated by these tools rarely work, simply because they are not holistic. These tools deal with parts of the organization rather than the whole. Although it is possible to optimize the operation of a part or a subsystem via this approach, the overall operation of the system may be affected adversly. Although it may not be optimal, a satisfactory solution for the overall system can be found if the crucial interactions and the subsystems are taken into account as a whole. The principle "a system is more than the sum of its parts" suggests that systems' behavior can be understood well if one understands the emergent system properties that arise only when parts interact with each other. This phenomenon was observed by many reaserchers in process re-engineering (BPR) projects. It appears that the main reason behind the failure of many of these projects is that there was too much concentration on subsystem re-engineering; crucial interactions such as human-organization relationships were ignored.

The limitations and inadequacies of hard systems thinking become fairly obvious in the 1980's due to the increasing complexity of contemporary systems. Soft systems thinking emerged as a response to overcome these difficulties and enable systems people to develop acceptable solutions to multi-disciplinary and complex problematic situations. Jackson classifies all important hard and soft systems methodologies and reviews them in a critical manner [Jackson, 2000 and 2003]. His classification, from social sciences point of view, includes the following groups: (a) The Functionalist Systems Approach; (b) The Interpretive Systems Approach; (c) 
The Emancipatory Systems Approach; (d) The Postmodern Systems Approach; (e) Critical Systems Thinking.

The Functionalist Aapproach includes Hard OR, Systems Engineering, Cybernetics, System Dynamics, Living Systems Theory, Autopoiesis, and Complexity Theory. Here systems appear as objective aspects of reality independent of observers. Their behavior is analyzed via the methods of the natural sciences, and this knowledge is used to improve their efficiency or efficacy of the system. In contrast, the assumption that everbody percieves reality the same way is rejected in soft systems thinking; perceptions are multiple and environment is plutralistic. Within the functionalist approach, there is a group of methodologies where "hard facts" are used throughout the study, and this kind of approach is commonly referred as "Hard Systems Thinking". Systems Theory provides theoretical background to all these methodologies. In regard to relating methodologies to problem contexts, Jackson [2003] suggests that "Hard Systems Thinking" is applicable to "simple systems-unitary participant" types of problems. Methodologies known as System Dynamics, Organizational Cybernetics and Complexity Theory are considered suitable for "complex systems-unitary participant situations". Similarly, Soft Systems Approaches are found to be applicable to both "simple systems-pluralist participants" and "complex systems-pluralist participants", Emancipatory Systems Thinking to "simple systems-coercive participants", and Postmodern Systems Thinking to "complex systems-coercive participants".

Probably the most important "break away" of the soft school from the hard school is related to the concept of objectivity. The claim of "objectivity" of classical science is found to be problematic in soft systems school; it is seen as nothing but an illusion. It is argued that it is meaningless to formulate objective aims and objective means in complex situations. The actors involved in the process are bound to have different perspectives of the problematic situation or the reality, and they will likely suggest different solutions. For instance, Soft Systems Methodology (SSM), one of the well-known methodologies, developed by Checkland (Checkland and Scholes, 1990), (Checkland, 1993), embraces a paradigm of learning rather than viewing the world as systems whose performance can be optimized by following systematic procedures. This way of thinking can also be seen in other soft methodologies, such as Warfield's Interactive Management, Churchman's Social Systems Design, Mason and Mitroff's Strategic Assumption Surfacing and Testing, Ackoff's Social Systems Sciences, Senge's Systems Thinking, Soft OR, Soft System Dynamics, and Soft Cybernetics. The interested reader should also look at Mingers and White (2010) and Mingers (2001) for detailed reviews of "hard and soft system schools", and their approaches to complexity. 
The methodology-problem context issue is also addressed by Kurtz and Snowden [2003]. They developed a framework, called Cynefin sense-making framework, classifying systems as follows: Known, Knowable, Complex, and Chaos. The Known systems are systems that have perceivable and predictable cause and effect relationships, and can be handled via Sense-Categorize-Respond types methodologies (e.g. process re-engineering). In the Knowable category, cause and effect are separated over time and space, and Sense-Analyze-Respond type methodologies are suitable. Complex systems, on the other hand, are viewed as systems with cause and effect relationships that are coherent in retrospect and do not repeat; apparently, the appropriate methodologies for this category are the Probe-Sense-Respond type (e.g. pattern management). In chaotic systems, cause and effect relationships are not perceivable, and can be handled only by Act-Sense-Respond approach (e.g. crisis management). Although it is not possible to draw clear lines between different systems and different problem categories, this categorization helps us to develop a picture where the problem situation can be related to a methodology or to a set of methodologies (multi-methodogical approach).

\section{Systems Thinking and Decision Making in Complexity}

As human beings, we make various decisions every day. Some of these decisions produce undesirable results, while the others do not. Some decisions taken in the midst of complexity may produce important consequences, whether they are good or bad. In most cases, the decision maker is a group of people or an organization rather than an individual. The culture of the organization or institution then becomes a significant parameter to be considered. In regard to global matters, Skyttner (2001 and 2006) suggests that the world society and its institutions are not functioning effectively because the old worldview has not been kept up to date with contemporary changes. The worldview of an organization is certainly an important factor that shapes its culture, and it also shows how adaptive the organization is. Surely, adaptivity requires strong organizational learning capabilities, both technically and socially. All organizations are socio-technical systems by their nature, and the social aspects are as important as the technical aspects. As discussed earlier, hard systems thinking is not suitable for understanding and dealing with such complexity; we need to look into soft system approaches. Hitchins (2003) has quite a radical suggestion for handling socio-technical systems. He thinks that "we do not need to fully understand the incomprehensible complex human-system interaction" and suggests that "we need to adopt an accelerated evolutionary approach by building complex adaptive socio-technical systems". The 2020 vision of Systems Engineering published by INCOSE (International Council on Systems Engineering) is also concerned with the increasing complexity of systems. Their prediction is that "de- 
velopments will urge systems enginers to integrate social and technological aspects of complex systems" (INCOSE, 2005) - it is also argued that developments in genetics and technology will make significant contributions to this effort. The reader will find detailed discussion on socio-technical systems in Jackson (2000 and 2003), Maani, et.al. (2007), Mingers, t.al. (2010 and 2011) and Yurtseven, et.al. (2012).

In general, there are actors with differing goals and preferences, and with different perceptions in all organizations. In addition to the organizational culture, personal inclinations of people involved may also play some role in decision making. Personal inclinations affect the decision outcome considerably if there are rapid changes in the dynamics of the environment, particularly the external environment; some people are more reluctant to take risks than others. Obviously, decision making processes that are designed for stable and slowly changing conditions will not work in a rapidly changing environment. Hummelbrunner and Williams (2011) think that managing complexity requires the principles of decentralization and collaboration, in additon to adaptivity. It is important to remember that the degree of decentralization needs to be adjusted properly to be useful, depending on the characteristics of the organization.

There are some studies that specifically address complexity decision making via holistic or systems approach. Research conducted at Santa Fe Institute attempts to unify some of the core system concepts into a model known as complex adaptive systems (Snyder, 2013). The argument is that the emergent properties of complex systems can be modeled and operated relatively more effectively as complex adaptive systems. Aelker, et. al. (2013) discusses this issue with some depth in their work. Sondoss et.al. (2015) handle the complexity in a viticulture irrigation management system in South Australia. They present a step-wise methodology that integrates qualitative information into formal simulation models, involving cognitive mapping and agent based modelling approaches. The resulting structure seems to capture the richness of decision making and mental models. Pagani and Otto (2013) adopts qualitative mapping theory building and quantitative group model building approaches in a computer-based system modeling environment for market startegy development. They claim that this holistic apparoach enhances the quality of the decision processes. Carlman, et.al. (2014) relate the complexity issue to sustainability in decision making processes, particularly to ecological systems. The decision structure developed in the study provides communication and collaboration between a technical-scientific group and social scientists via a holistic outlook. Swami's work (2013), on the other hand, views decision making under the broad topic of executive functions or cognitive processes that are regulated. This holistic approach includes theories and concepts from psychology, behavioral eco- 
nomics, operations research, and managerial practice. Schiuma, et.al. (2012) report a systems thinking-based framework where knowledge assets are translated into organizational value for making good decisions. Similarly, the work by Wiek, et.al. (2009) presents a framework called The Transdisciplinary Integrated Planning and Synthesis (TIPS), which is mainly based on soft OR methods. This particular framework makes use of a multi-methodological approach involving cognitive skills and habits of the stakeholders, and experts and their mutual and joint transdisciplinary learning processes. This framework was applied in a large-scale regional planning process in Switzerland. The interested reader can find a number of models/methods/systems that have been developed to underpin sustainable decision-making in environmental impact assessment, life cycle assessment, ecological footprints, cost benefit analysis, etc. (Sondoss, et. al., 2015), (Carlman, et. al., 2014), (Schiuma, et. al., 2012), (Petkov, et. al., 2009) and (Taylor, et. al., 2011).

\section{The Framework}

Pownall (2012) describes different perspectives of decision making and gives a useful classification of decision making methods. These perspectives can be summarized as follows: (a) a qualitative perspective which is an integrative approach (or rational normative); (b) a perspective achieved by combining quantitative and behavioral disciplines in an interdisciplinary manner; (c) an interlocking perspective where the engagement of one perspective limits the use of other perspectives; (d) a cause-effect view where decisions taken are interrelated across organizational events.

Systems thinking-based decision making does not exclude perspectives (a), (b) and (d). Furthermore, it removes the limitations implied by (c). Figure 1 shows the relative positions of different approaches as a function of changing complexity. The sequential decision making (problems are formulated as a sequence of "independent" decisions) is algorithmic; hence it belongs to the least complex situations shown at the left of the scale. The anarchical decision making is far on the right of the scale, indicating that they involve highly complex situations. The RAT (rational-normative model of decision making) and three-phased (problem identification, solution development, and solution selection) models are closer to sequential decision making, respectively, and heuristic models are closer to the other edge.

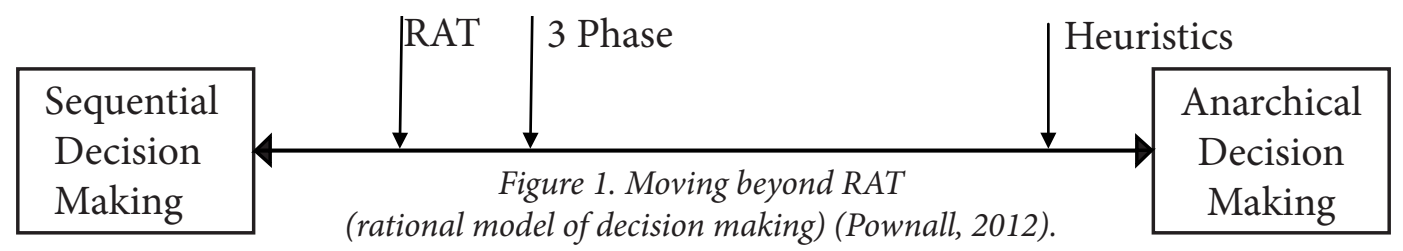


The normative or rational models are based on the assumption that all relevant and pertinent information is available for optimal decision making. These types of problems are mostly seen in investment analysis, project management, cost-benefit analysis, etc. The three-phased model, unlike the sequential decision making, recognizes that the solution development and solution selection phases cannot be separated, and that the corresponding cognitive processes overlap and can occur simultaneously. As we approach to the right side of the scale, the decision processes become more complicated since they involve decisions made by groups in a political context. As one approaches to Anarchical Decision Making region, the decision makers need to make use of heuristic approaches. The models here tend to become more "irrational" where human decision values are incorporated into the process. The decision maker may incorporate any of these models or a combination of them in systems thinking-based approach.

\section{The framework is consisted of five parts:}

Fundamentals; Rational Models with Quantitative Methods; Rational Models with Qualitative Methods; Systems Thinking-Based Decision Makings; Optional Material.

Part I: The Fundamentals: Introduction to Effective Decision Making The objective here is to explore the concept that decision-making process is partly science and partly art. Different concepts of rationality and the resulting approaches are discussed in general terms, ranging from normative rational view to anarchistic and heuristic views.

Part II: Rational Models with Qualitative Methods and Analysis

The main theme here is to cover the development of rational models based on forecasting and regression techniques.

Part III: Rational Models with Quantitative Methods and Analysis

This section covers methods based on probability theory, such as decision trees and related decision analysis and queuing theory.

Part IV: Systems Thinking-Based Decision Making

This part starts with the Fundamentals of Systems Thinking and provides an introduction to soft system methodologies. Some case studies are discussed to demonstrate the strengths of system thinking-based decision making. Selection of case studies and the methodology or methodologies will depend on the instructor's choice.

Part V: Optional Material

Heuristic Decision Making and Group Decision Making:

This section includes the fundamentals of decision making approaches that emphasize cognitive, heuristic, and group behavior aspects. 
Knowledge Management and Decision Enhancing Decision Making: The objective in this section is to teach the fundamentals of knowledge management concepts, and (intelligent) decision support systems, together with the relevant IT. The technological aspects of this topic may be found at (Muller, et. al., 2014), (Khan, et. .al. 2014), (Laudon, et.al, 2013) and (Kendall, et. al. 2011).

The reader should note that Monte Carlo Modeling can also be considered as a Systems Thinking- Based methodology (Pownall 2012, Parnell, et.al. 2011, Taylor III, 2013). This approach is very helpful when complete information is not available and/or the decision making process cannot be formulated in a manageable analytical form. In Monte Carlo modeling, the potential outcomes of a decision problem are assigned weights via the use of pseudo random numbers. The decision maker can then produce decisions without referring to the decision context. In this way, the difficulty involved in the explicit treatment of uncertainty is avoided. Due to its versatility, Monte Carlo modeling is covered in many undergraduate textbooks nowadays (Hazelrigg, 1996), (Daellanbach, 2005), (Parnell, et. al. 2011), (Krajewski, et. al., 2013) and (Taylor III, 2013).

As a final note, instructors are reminded that students neeed to know how to include soft indicators (such as morale, commitment, burnout, capacity for learning) together with hard indicators (key performance indicators or critical success factors) into the modeling of complex decision making problems. They also need to be comfortable with simulation tools; it is well known that simulation models are useful in handling complex systems. System modeling, model validation, policy analysis, scenario generation and strategy development studies can be conducted easily via intelligent software packages such as Stella these days. The interested reader should see Maani, et.al., (2007), Aelker, et.al, (2013), Mingers, et.al. (2010), and Yurtseven, et.al, (2012).

At present, sufficient information is not available to evaluate the effectiveness of the above framework. However, a positive initial response was received from the fourth year industrial engineering students when some material from Part IV of the framework was introduced into the Fundamentals of Systems Engineering course.

\section{Conclusions}

It was argued that the traditional or hard OR/MS paradigm is not adequate for complex decision making situations; it needs to be complemented by soft system thinking approaches in university educational programs. Soft system methodolo- 
gies cover a wide range of approaches that hard methodologies can not capture and allow the decision maker to handle a complex situation in its full system context. The framework presented in the study will help instructors to design contemporary courses that include complexity decision making processes. In this way, graduating students will have a broader vision and will have some confidence in handling complexity in real life. Future research will be directed towards measuring the degree of success of the framework proposed.

\section{References}

Aelker, Judith, Bauernhans, T., and Ehm, H. (2013) "Managing complexity in supply chains: A dis cussion of current approaches on the example of the semiconductor industry", Procedia CIRP 7 ( 2013 ) $79-84$.

Carlman, I., Grönlund, E. and Longueville, A. (2014) "Models and methods as support for sustain able decision- making with focus on legal operationalization", Ecological Modelling xxx (2014) $\mathrm{xxx}-\mathrm{xxx}$ (Article in Press).

Checkland, P., (1993), Systems Thinking, Systems Practice, Wiley.

Checkland P. and Scholes J. (1990), Soft Systems Methodology in Action, Wiley.

Daellanbch, H.G., D.C. McNickle and S. Dye [2005] Management Science: Decision-Making Through Systems Thinking, Pelgrave Macmillan.

Gorze-Mitka, I. and Okreglicka, M. (2014) "Improving Decision Making in Complexity Environ ment", Procedia Economics and Finance, 16, 402 - 409.

Hazelrigg, G.A. (1996) Systems Engineering: An Approach to Information-Based Design, Prentice Hall. Hitchins, D.K., (2003), Advanced Systems Thinking, Engineering, and Management, Artech House. Hummelbrunner, R. and B. Williams B. (2011) Systems Concepts in Action : A Practitioner's Toolkit Stanford, Calif: Stanford Business Books.

INCOSE, Systems Engineering Vision 2020, Version 1.5, November 26, 2005.

Jackson, M. C., (2000), Systems Approaches to Management, Kluwer.

Jackson, M.C., (2003), Systems Thinking: Creative Holism for Managers, Wiley.

Jamali D. (2005), "Changing management paradigms: implication for educational institutions", Journal of Management Development, vol.24, 2005,pp. 104-105.

Kendall, K.E. and J.E. Kendall (2011) System Analysis and Design, Pearson.

Khan, R.A. (2014) "Business Intelligence: An Integrated Approach", International Journal of Mana gement and Innovation, Volume 6 Issue 2 (2014) 21.

Krajewski, L.J., L.P. Ritzman and M.K. Malhorta (2013) Operations Management: Processes and Supply Chains, Pearson.

Kutz, C. and Snowden, D.J., (2003), “The New Dynamics of Strategy: sense-making in a complexcomplicated world", IBM Systems Journal 42(3): 462-483.

Laudon, C.K. and J.P. Laudon (2104) Management Information Systems, Pearson.

Maani, Kambiz E., and R.Y. Cavana, (2007), Systems Thinking and System Dynamics: Managing Change and Complexity, Pearson - New Zealand, 2007.

Mingers, J. and L. White (2010) "A review of the recent contribution of systems thinking to oper ational research and management science", European Journal of Operational Research 207 (2010) 1147-1161.

Mingers, J. (2011) “Soft OR comes of age—but not everywhere!” Omega 39 (2011) 729-741. Müller, R.M., S. Linders, and L. Ferreira (2010) "Business Intelligence and Service-oriented Archi tecture: A Delphi Study”, Information Systems Management, 27:168-187, 2010 
Pagani, M. and Otto, P. (2013), "Integrating strategic thinking and simulation in marketing strategy: Seeing the whole System”, Journal of Business Research, 66, 1568-1575.

Parnell, G.S.(Ed.), Driscoll, P.J.(Ed.), Henderson, D.L. (Ed.) (2011) Decision Making in Systems En gineering and Management, Wiley.

Petkov, D., Petkova, O. Andrew, T. and Nepal, T. “Mixing Multiple Criteria Decision Making with soft systems thinking techniques for decision support in complex situations", Decision Sup port Systems, 43, 1615-1629. 2009.

Pownall, I (2012) Effective Decision Making: An Introduction, Ventus ApS.

Schiuma, G., Carlucci, D. and Sole F. (2012) "Applying a systems thinking framework to assess know ledge assets dynamics for business performance improvement", Expert Systems with Applic ations, 39, 8044-8050.

Skyttner, L., (2001), General Systems Theory: Ideas \& Applications, World Scientific.

Skyttner, L., (2005), General Systems Theory: Problems- Perspectives- Practice, World Scientific.

Sondoss, Elsawah Joseph H.A. Guillaume, Tatiana Filatova Josefine Rook, Anthony J. Jakeman (2015) "A methodology for eliciting, representing, and analysing stakeholder knowledge for decision making on complex socio-ecological systems: From cognitive maps to agent-based models", Journal of Environmental Management 151, 500-516.

Snyder, S. (2013), “The Simple, the Complicated, and the Complex: Educational Reform Through the Lens of Complexity Theory", OECD Education Working Papers, No. 96, OECD Publish ing.p.11.

Swami, S. (2013) “Executive functions and decision making: A managerial review”, IIMB Manage ment Review, 25, 203-212.

Taylor, T. R. B., David N. Ford, Shari A. Yvon-Lewisc and Eric Lindqui, (2011), "Science, engineer ing, and technology in the policy process for mitigating natural-societal risk", System Dynam ics Review. 27, 173-194.

Taylor III, B.W. (2013) Introduction to Management Science, Pearson.

Yurtseven, M.K., and W. W. Buchanan [2012] "Dynamical System Theory and System Dynamics: Educational Issues”, Technology Interface International Journal, Spring- Summer, pp. 96-103.

Wiek, A. and Walter, A.I. (2009)"A transdisciplinary approach for formalized integrated planning and decision-making in complex systems", European Journal of Operational Research, 197, 360-370. 